\title{
Quality of Health Care in Resource Limited Settings-Patients' Satisfaction Survey at a Mission Hospital in South East, Nigeria
}

\author{
Olaronke Fayosi Afolabi, ${ }^{1,2,3}$, Collins Nwachi Ugwu',2,3, Chukwuemeka Okorie Eze', \\ Djobissie Fankou Serges-Anthanase ${ }^{3}$, Chiemela Okezie Onwuchekwa ${ }^{3}$, Moses Agha Ude ${ }^{3}$
}

${ }^{1}$ Department of Internal Medicine, Alex-Ekweueme Federal University Teaching Hospital, Abakaliki, Nigeria

${ }^{2}$ African Institute for Health Policy and Health Systems, Ebonyi State University, Abakaliki, Nigeria

${ }^{3}$ Mater Misericordiae Hospital, Afikpo, Nigeria

Email: olaronke.afolabi@yahoo.com

How to cite this paper: Afolabi, O.F., Ugwu, C.N., Eze, C.O., Serges-Anthanase, D.F., Onwuchekwa, C.O. and Ude, M.A. (2021) Quality of Health Care in Resource Limited Settings-Patients' Satisfaction Survey at a Mission Hospital in South East, Nigeria. Open Journal of Internal Medicine, 11, 201-209.

https://doi.org/10.4236/ojim.2021.114016

Received: September 9, 2021

Accepted: November 13, 2021

Published: November 16, 2021

Copyright $\odot 2021$ by author(s) and Scientific Research Publishing Inc. This work is licensed under the Creative Commons Attribution International License (CC BY 4.0).

http://creativecommons.org/licenses/by/4.0/

\begin{abstract}
Introduction: Quality healthcare is a major contributor to health disparities and inequalities in resource limited settings. Patient satisfaction remains an important and valuable method of assessing the quality of care. Aim: This study assessed patients' satisfaction with quality of inpatient clinical care in a mission hospital in a semi urban setting. Methods: The study was a cross-sectional study carried out on 140 inpatients at a mission hospital in Afikpo, South East Nigeria. Data was collected using pretested structured questionnaires designed on a five-point likert scale with 1 indicating the lowest and 5 indicating the highest scale. Knowledge of factors contributing to quality of care and satisfaction in the following domains: patient-staff relationship, patient-staff (doctors/nurses) communication, facility convenience, technical aspect of care (availability of equipment, drugs and adequacy of staff) and overall general satisfaction were measured. Operationally, patients who rated 3 points and above were considered satisfied while ratings less than 3 points were considered dissatisfied. Results: Knowledge of factors contributing to quality of care was $4.65 \pm 0.48$. General satisfaction rated $4.22 \pm$ 0.52 . Specifically, the different domains had the following scores: inter personal relationship $4.28 \pm 0.81$, technical aspect of care (availability of drugs, equipment and medical personnel) $4.29 \pm 0.57$ and facility convenience 4.21 \pm 0.51 . Conclusions: Knowledge of factors contributing to quality of care and overall patients' satisfaction with inpatient care were good and comparable with patients' satisfaction with tertiary health institutions in Nigeria. Mission hospitals may serve as excellent alternatives to government hospitals in resource limited settings to promote health equity across populations.
\end{abstract}




\section{Keywords}

Inpatients, Satisfaction, Mission Hospital, Nigeria

\section{Introduction}

In recent times, there is growing consensus that assessment of quality of care should be based on patients' satisfaction studies. Quality in health care is defined as the best possible health outcomes that can be attained with the available resources and that are compatible with the patient's values and preferences [1]. The quality of care received by the patients is determined by interaction of numerous factors; hence measurement of quality of care includes both tangible and intangible elements [2]. Factors like cost of services, quality of the facilities, quality of process, quality of interaction and communication with patients have the greatest effect on the overall patients' satisfaction [3]. Other factors affecting the satisfaction and dissatisfaction of patients include access to health care, competent and skilled health personnel, financing, waste disposal and government policy [4] [5]. Patients' satisfaction studies are therefore increasingly being considered an important dimension of quality of care and the extent of utilization of health services.

Many studies have shown that patients' satisfaction has many benefits. Utilization of health services is better when the quality of care is perceived to be good [6] while low quality of care is a barrier to utilization [7].

Studies that have been done in Nigeria on patients' satisfaction focused mainly on government hospitals which are more in the urban area. This study was therefore generally aimed at assessing patients' satisfaction with quality of inpatient clinical care and specifically to assess knowledge of patients on factors contributing to quality of care, ascertaining their satisfaction with some selected quality of care indices like patient-staff communication and interpersonal relationship, convenience of facility and technical aspect of care; and to assess patients' general satisfaction and willingness to recommend the facility to others in a mission hospital in South-Eastern Nigeria.

\section{Study Design and Methodology}

This study was cross sectional and hospital based. The place of study was at Mater Misericordiae Hospital, Afikpo; a catholic mission health institution serving Afikpo town and neighboring communities in Ebonyi state, South-East, Nigeria. The study was carried out between January, 2018 and August, 2018.

Eligible and consenting patients were drawn consecutively from the medical, surgical and private wards of the hospital. Consenting parents/guardians of children on admission in the pediatric ward were also involved in the study.

The study was approved by the ethics committee of the hospital and informed verbal consent was obtained from the participants. 
Inclusion criteria included patients aged 16 years and above with at least one night stay on admission in the medical, surgical and private wards. Parents of children on admission for at least one night in the children's ward were also involved while patients who declined consent, patients in the accident and emergency care unit and members of staff on admission were excluded from the study.

Data were collected using pretested, structured 24 item questionnaire designed by the authors using information from literature review and previous studies on patients' satisfaction and quality of care [8] [9]. Bio data and relevant socio demographic information about the patients were also collected. This included age, sex, occupation, marital status, educational status, occupation and number of days on admission.

Answers were scored using the likert scale. Knowledge items were scored on a five point likert scale as follows: 5: extremely relevant, 4: very relevant, 3: relevant, 2: irrelevant, 1: very irrelevant. Each satisfaction item was scored on a five point Likert scale as follows: 5: extremely satisfied, 4: very satisfied, 3: satisfied, 2: dissatisfied, 1: extremely dissatisfied.

Operationally, satisfaction referred to the score of 3 points or more in specific domain of care evaluated. Patient-staff relationship refers to the staff caring attitude, friendliness and courtesy; while patient-staff communication refers to willingness to listen and answer questions, giving explanation and instructions to the patients in a way that is understood. Facility convenience refers to the cleanliness and comfort of the wards while technical aspect of care refers to availability of equipment, drugs and adequacy of staff.

The results generated were analyzed using software Statistical Package for Social Sciences (SPSS) version 21.0, Microsoft cooperation, Inc. Chicago, IL, USA for the calculation of mean, frequencies and percentages.

\section{Results}

\subsection{Socio Demographic Characteristics}

The age of the respondents ranged from 16 years to 80 years. There were 72 males $(51.43 \%)$ and 68 females $(48.57 \%)$ with male to female ratio 1.1:1. 28 $(20.00 \%)$ had no education and $39(21.43 \%)$ had only primary education. 38 (27.14\%) respondents had secondary education as the highest formal education and $46(31.43 \%)$ had tertiary education (Table 1$)$.

\subsection{Ward Distribution and Days on Admission}

Patients' population was drawn from the various wards respectively. Male medical ward 39 (27.83\%), female medical ward 34 (24.29\%), male surgical ward 14 (10.00\%), female surgical ward 22 (15.71\%), children's ward $17(12.14 \%)$ and private ward 14 (10.00\%) (Table 2).

$96(68.57 \%)$ of the patients were new patients using the facility while 44 (31.43\%) were return patients. $77.14 \%$ of respondents had been on admission for 
Table 1. Socio demographic characteristics of the respondents.

\begin{tabular}{|c|c|}
\hline Demographic Characteristics & Number of Respondents (\%) \\
\hline \multicolumn{2}{|l|}{ Age of Respondents (Years) } \\
\hline$<20$ & $14(10.00)$ \\
\hline $20-30$ & $40(28.57)$ \\
\hline $30-50$ & $22(15.71)$ \\
\hline $40-50$ & $15(10.74)$ \\
\hline $60-70$ & $19(20.71)$ \\
\hline$>70$ & $20(14.29)$ \\
\hline Total & $140(100 \%)$ \\
\hline \multicolumn{2}{|l|}{ Gender } \\
\hline Male & $72(51.43)$ \\
\hline Female & $68(48.57)$ \\
\hline Total & $140(100 \%)$ \\
\hline \multicolumn{2}{|l|}{ Educational Status } \\
\hline None & $28(20.00)$ \\
\hline Primary & $39(21.43)$ \\
\hline Secondary & $38(27.14)$ \\
\hline Tertiary & $29(20.72)$ \\
\hline Postgraduate & $15(10.71)$ \\
\hline Total & $140(100 \%)$ \\
\hline
\end{tabular}

Table 2. Ward distribution and number of days on admission of respondents.

\begin{tabular}{cc}
\hline Parameter & Number (\%) \\
\hline Ward & $39(27.86)$ \\
Male medical ward & $34(24.29)$ \\
Female medical ward & $14(10.00)$ \\
Male surgical ward & $22(15.71)$ \\
Female surgical ward & $17(12.14)$ \\
Children ward & $14(10.00)$ \\
Private ward & $140(100 \%)$ \\
Total & $108(77.14)$ \\
\hline Days on Admission & $18(12.86)$ \\
\hline 10 & $14(10.00)$ \\
Total 20 & $140(100.00)$
\end{tabular}


$<10$ days, $12.86 \%$ for 11 - 20 days and $10.00 \%$ for more than 20 days (Table 2).

\subsection{Quality of Inpatient Care Assessment}

The average score on knowledge of factors contributing to quality of care was $4.65 \pm 0.48$ ('Table 3 ). Overall general satisfaction rated $4.22 \pm 0.52$. Doctors' attitude was rated $4.35 \pm 0.70$ while nurses' attitude was rated $4.28 \pm 0.81$; ward orderlies friendliness was rated $4.18 \pm 0.74$ while the attitude of other staff was rated $3.93 \pm 0.90$ (Table 4 ). Mean rating of staff interpersonal relationship was $4.24 \pm 0.54$; mean rating of facility convenience was $4.21 \pm 0.51$ while technical aspect (availability of medical personnel, equipment and drugs) rated $4.29 \pm 0.57$ (Table 4 and Table 5).

\subsection{Willingness to Recommend the Facility}

$134(95.71 \%)$ of the respondents were willing to recommend the facility while 6 (4.29\%) did not show the willingness (Figure 1).

Table 3. Rating of knowledge of factors contributing to quality of care.

\begin{tabular}{cc}
\hline Item & Mean \pm SD \\
\hline Availability of appropriate equipment & $4.72 \pm 0.58$ \\
Availability of skilled personnel & $4.65 \pm 0.64$ \\
Availability of prescription drugs in the hospital & $4.71 \pm 0.61$ \\
Friendliness of hospital staff & $4.67 \pm 0.63$ \\
Communication about Medicare & $4.56 \pm 0.64$ \\
Conducive hospital environment & $4.60 \pm 0.83$ \\
Mean & $4.65 \pm 0.48$ \\
\hline
\end{tabular}

Table 4. Rating of interpersonal relationship and communication skills.

\begin{tabular}{cc}
\hline Item & Mean \pm SD \\
\hline Caring attitude of nurses & $4.28 \pm 0.81$ \\
Friendliness of doctors & $4.35 \pm 0.70$ \\
Courtesy of ward orderlies & $4.18 \pm 0.74$ \\
Friendliness of other staff (Lab, X-ray) etc & $3.93 \pm 0.90$ \\
Willingness to listen carefully & $4.50 \pm 0.71$ \\
Taking time to answer questions & $4.33 \pm 0.82$ \\
Explaining things in way that is understood & $4.38 \pm 0.71$ \\
Instructions regarding medicare & $4.24 \pm 0.79$ \\
Willingness to listen carefully & $4.24 \pm 0.83$ \\
Taking time to answer questions & $4.13 \pm 0.92$ \\
Explaining in a way that is understood & $4.24 \pm 0.79$ \\
Instructions regarding Medicare & $4.16 \pm 0.80$ \\
Mean & $4.24 \pm 0.54$ \\
\hline
\end{tabular}


Table 5. Rating of facility convenience and technical aspect of care.

\begin{tabular}{cc}
\hline Item & Mean \pm SD \\
\hline Facility Convenience & \\
\hline Cleanness of the ward & $4.27 \pm 0.78$ \\
Comfort/convenience of the ward & $4.17 \pm 0.79$ \\
Mean & $\mathbf{4 . 2 1} \pm \mathbf{0 . 5 7}$ \\
\hline Technical Aspect of Care & $4.30 \pm 0.72$ \\
Availability of drugs & $4.30 \pm 0.68$ \\
Availability of necessary equipment & $4.15 \pm 0.73$ \\
Adequacy of doctors and nurses & $4.40 \pm 0.77$ \\
Adequacy of other staff & $\mathbf{4 . 2 9}$ \\
Mean & $\mathbf{0 . 5 7}$ \\
\hline
\end{tabular}

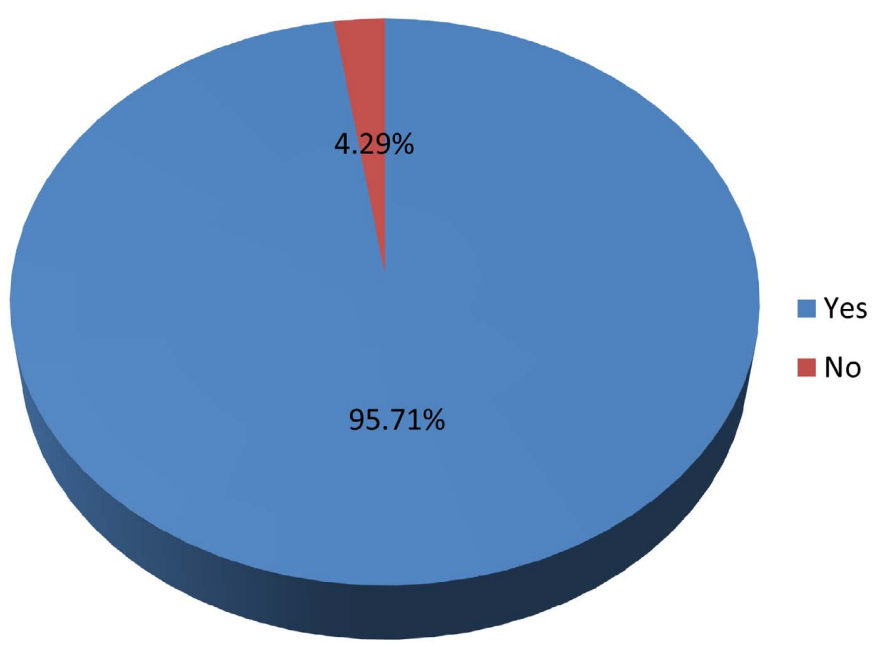

Figure 1. Willingness to recommend the facility.

\section{Discussion}

This study showed that knowledge of factors contributing to quality of care was good among the respondents. This emphasizes the fact that patients have their expectations which the health care providers should aim to meet. This study also showed that overall patients' satisfaction with the quality of inpatient care they received was good. Users of health facilities differ in their satisfaction with the quality of care. Studies done in tertiary institution in South East Nigeria [10], South West Nigeria [11] and Northern Nigeria [9] generally reported high satisfaction rate. Overall satisfaction rate of 3.1 was reported at a tertiary institution in Umuahia, Abia state, South East Nigeria [10]. Other studies done at primary health facilities in urban areas in Nigeria also showed high satisfaction level [12] [13] [14]. Satisfaction rates in this study were comparable to those obtained from tertiary institutions in Nigeria.

Patients' satisfaction with staff interpersonal relationship was good. The atti- 
tude of doctors and nurses were rated high. This study demonstrated that patients were satisfied with communication with doctors and nurses though doctors were rated higher. High rating of doctors was similar to reports from Benin City, Edo State, Nigeria [15] and Umuahia, Abia State, Nigeria [10] but was in disparity with low rating of patient, provider attitude in Ilorin, North Central Nigeria [16] and Eastern Ethiopia [17]. A lower rating of the attitude of other staff of the hospital was reported. It is therefore necessary to seek ways to improve their attitude to patients. Staff attitude is generally perceived to be better in mission hospitals and private hospitals when compared with state owned general hospitals. Good patient, staff communication is important to improve compliances and adherence to treatment [18] [19].

The patients were satisfied with the cleanliness and convenience of the wards. This is similar to findings reported in South Trinidad and Kano, Nigeria [9] but dissimilar to findings in Eastern Ethiopia where patients were not satisfied with cleanliness of health facility. This finding also buttressed the fact that environmental factors may influence perception of quality of care and patients' satisfaction [17] [20].

Patients also demonstrated satisfaction with the adequacy of staff, availability of drugs in the hospital and availability of necessary equipments. This is commendable in a mission hospital in a resource limited environment. The willingness of majority of the patients (95.71\%) to recommend the facility to others also buttressed their high level of satisfaction with the quality of care received.

This study had some limitations. This study was focused on inpatient care. It may not be a general conclusion about care in the outpatient clinics and the emergency rooms.

\section{Health Policy Implication}

Patients' satisfaction is an essential health policy issue. A good quality assessment programme should focus on vital areas of accountability in the health system. The effective use of information generated is crucial in decision making in maintaining and upgrading the health care system. It is very important in administration, planning, monitoring and evaluation of health care system. It offers profound insight into areas of strengths, weaknesses and necessary measures needed to improve quality of care in the health care system.

Periodic appraisal of health systems is imperative to get useful feedbacks for improvement of health services.

\section{Conclusion}

Knowledge of factors contributing to quality of care was good among patients in this study. Patients' satisfaction rate in this study was high and the majority of the patients were willing to recommend the facility to others. Mission hospitals may serve as excellent alternatives to government hospitals in resource limited settings to promote health equity across populations. 


\section{Acknowledgements}

The authors are grateful to Prof. Chigozie Jesse Uneke for his contributions to the design of the research.

\section{Competing Interests}

The authors declare no conflicts of interest regarding this publication.

\section{References}

[1] Makela, M., Booth, B. and Roberts, R. (2001) Family Doctors' Journey to Quality. Stakes, Helsinki.

[2] Mosadeghrad, A.M. (2012) A Conceptual Framework for Quality of Care. Mater Sociomed, 24, 251-261. https://doi.org/10.5455/msm.2012.24.251-261

[3] Andaleeb, S.S. (1998) Determinants of Customer Satisfaction with Hospitals: A Managerial Model. International Journal of Health Care Quality Assurance, 6, 181-187. https://doi.org/10.1108/09526869810231541

[4] Oermann, M.H. (1999) Consumers' Descriptions of Quality Health Care. Journal of Nursing Care Quality, 14, 47-55. https://doi.org/10.1097/00001786-199910000-00006

[5] Ankita, M., Abbduwahus, A., Privor-Dumm, L. and Wonodi, C. (2015) Basket Finds a Pool Arrangement to Finance Primary Health Care Delivery and Address Finding Flow in Nigeria. International Vaccine Access Centre (IVAC). Johns Hopkins Bloomberg School of Public Health.

[6] Onyeneho, N.G., Amazigo, U.V., Njepuome, N.A., Nwaogu, O.C. and Okeibunor, J.C. (2016) Perception and Utilization of Public Health Services in Southeast Nigeria: Implication for Health Care in Communities with Different Degrees of Urbanization. International Journal for Equity in Health, 15, Article No. 12. https://doi.org/10.1186/s12939-016-0294-Z

[7] Bakeera, S.K., Wamala, S.P., Galea, S., State, A., Peterson, S. and Pariyo, G.W. (2009) Community Perceptions and Factors Influencing Utilization of Health Services in Uganda. International Journal for Equity in Health, 8, Article No. 25. https://doi.org/10.1186/1475-9276-8-25

[8] Oforvwe, C.E. and Ofili, A.N. (2005) Indices of Patient Satisfaction in an African Population. Public Health, 119, 582-586. https://doi.org/10.1016/j.puhe.2004.10.012

[9] Iliyasu, Z., Abubakar, I.S., Abubakar, S., Lawan, U.M. and Gajida, A.U. (2010) Patients' Satisfaction with Services Obtained from Aminu Kano Teaching Hospital, Kano, Northern Nigeria. Nigerian Journal of Clinical Practice, 13, 371-378.

[10] Iloh, G., Ofoedu, J.N., Njoku, P.U., Odu, F.U., Ifedigbo, C.V. and Iwuamanam, K.D. (2012) Evaluation of Patients' Satisfaction with Quality of Care Provided at the National Health Insurance Scheme Clinic of a Tertiary Hospital in South-Eastern Nigeria. Nigerian Journal of Clinical Practice, 15, 469-474.

[11] Esimai, O.A. and Omoniyi-Esan, G.O. (2009) Wait Time and Service Satisfaction at Antenatal Clinics, Obafemi Awolowo University Ile-Ife. East African Journal of Public Health, 6, 309-311.

[12] Akinyinka, M.R., Adebayo, B.I., Wright, K.O. and Adeniran, A. (2016) Client Waiting Time in an Urban Primary Health Care Centre in Lagos. Journal of Community Medicine and Primary Health Care, 28, 17-24.

[13] Babatunde, O.A., Aiyenigba, E., Akande, T.M., Musa, O.I., Salaudeen, A.G., Baba- 
tunde, O.O., et al. (2013) Primary Health Care Consumers' Perception of Quality of Care and Its Determinants in North-Central Nigeria. Journal of Asian Scientific Research, 3, 775-785.

[14] Nnebue, C.C., Ebenebe, U.E., Adinma, E.D., Iyoke, C.A., Obionu, C.N. and Ilika, A.L. (2014) Clients' Knowledge, Perception and Satisfaction with Quality of Maternal Health Care Services at the Primary Health Care Level in Nnewi, Nigeria. Nigerian Journal of Clinical Practice, 17, 594-601.

[15] Ofili, A.N. and Ofovwe, C.E. (2005) Patients' Assessment of Efficiency of Services at a Teaching Hospital in a Developing Country. Annals of African Medicine, 4, 150-153.

[16] Abdosh, B. (2006) The Quality of Hospital Services in Eastern Ethiopia: Patients' Perspective. Ethiopian Journal of Health Development, 20, 199-200.

https://doi.org/10.4314/ejhd.v20i3.46854

[17] Akande, T.M. (2002) Patients' Perception on Communication between Patients and Doctors in a Teaching Hospital. Sahel Medical Journal, 5, 178-181.

https://doi.org/10.4314/smj2.v5i4.12824

[18] Joseph, C. and Nicholas, S. (2007) Patient Satisfaction and Quality of Life among Persons Attending Chronic Disease Clinics in South Trinidad, West Indies. West Indian Medical Journal, 56, 108-114.

[19] Perla, L. (2002) Patients Compliance and Satisfaction with Nursing Care during Delivery and Recovery. Journal of Nursing Care Quality, 16, 60-66.

https://doi.org/10.1097/00001786-200201000-00007

[20] Singh, H., Haqq, E.D. and Mustapha, N. (1999) Patients' Perception and Satisfaction with Healthcare Professionals at Primary Care Facilities in Trinidad and Tobago. Bulletin of the World Health Organization, 77, 356-360. 